\title{
Brief communication "Climatic covariates for the frequency analysis of heavy rainfall in the Mediterranean region"
}

\author{
Y. Tramblay, L. Neppel, and J. Carreau \\ Hydrosciences Montpellier, UMR5569, CNRS - IRD-UM1-UM2, Université Montpellier 2, Maison des Sciences de l'Eau, \\ Place Eugène Bataillon, 34095 Montpellier Cedex 5, France
}

Received: 26 April 2011 - Revised: 4 July 2011 - Accepted: 23 August 2011 - Published: 15 September 2011

\begin{abstract}
In Mediterranean regions, climate studies indicate for the future a possible increase in the extreme rainfall events occurrence and intensity. To evaluate the future changes in the extreme event distribution, there is a need to provide non-stationary models taking into account the nonstationarity of climate. In this study, several climatic covariates are tested in a non-stationary peaks-over-threshold modeling approach for heavy rainfall events in Southern France. Results indicate that the introduction of climatic covariates could improve the statistical modeling of extreme events. In the case study, the frequency of southern synoptic circulation patterns is found to improve the occurrence process of extreme events modeled via a Poisson distribution, whereas for the magnitude of the events, the air temperature and sea level pressure appear as valid covariates for the Generalized Pareto distribution scale parameter. Covariates describing the humidity fluxes at monthly and seasonal time scales also provide significant model improvements for the occurrence and the magnitude of heavy rainfall events. With such models including climatic covariates, it becomes possible to asses the risk of extreme events given certain climatic conditions at monthly or seasonal timescales. The future changes in the heavy rainfall distribution can also be evaluated using covariates computed by climate models.
\end{abstract}

\section{Introduction}

The frequency analysis techniques are commonly used for the estimation of the return periods of extreme hydrometeorological events, such as floods or heavy rainfall (Coles, 2001; Coles et al., 2003). In the recent years, several

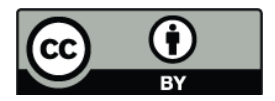

Correspondence to: Y. Tramblay

(ytramblay@gmail.com) studies have indicated a possible increasing trend in the occurrence and severity of the heavy rainfall events across the Mediterranean region (Goubanova and Li, 2007; Natsos and Zerefos, 2008; Giorgi and Lionello, 2008). Therefore, there is a need to assess the possible changes in the extreme precipitation distribution. The main way to incorporate the nonstationarity of climate into frequency models is to make their parameters dependent on time or other covariates (Katz et al., 2002). Several studies have analyzed the trends in heavy rainfall using extreme value models with time-dependent parameters (Pujol et al., 2007; Beguería et al., 2010). However, in order to produce future scenarios, there is a need to include in such models climatic covariates instead of time, since there is no evidence that the observed temporal trend would be the same in the future. The goal of this study is to identify relevant climatic covariates to be included in a frequency model for heavy rainfall.

\section{Study area}

The southern coastal area of France, corresponding to the Cévennes region, is often hit by heavy rainfall events causing catastrophic flash-floods during the fall season (Pujol et al., 2007). Daily rainfall from 44 Météo-France rain gauges in the South of the Cévennes-Vivarais region were used (Fig. 1), with daily rainfall between 1958 and 2008 and less than $2 \%$ missing data. The selected stations correspond to a homogeneous region with regard to extreme rainfall events, as shown in the regionalization proposed by Pujol et al. (2007). The heavy rainfall events, defined in the present study as daily rainfall exceeding the threshold of $100 \mathrm{~mm}$ during the fall season (September to November, with the highest frequency in October) have been extracted for each station. This threshold corresponds to events causing human losses and economic damage in the study area (Boissier and Vinet, 2009).

Published by Copernicus Publications on behalf of the European Geosciences Union. 


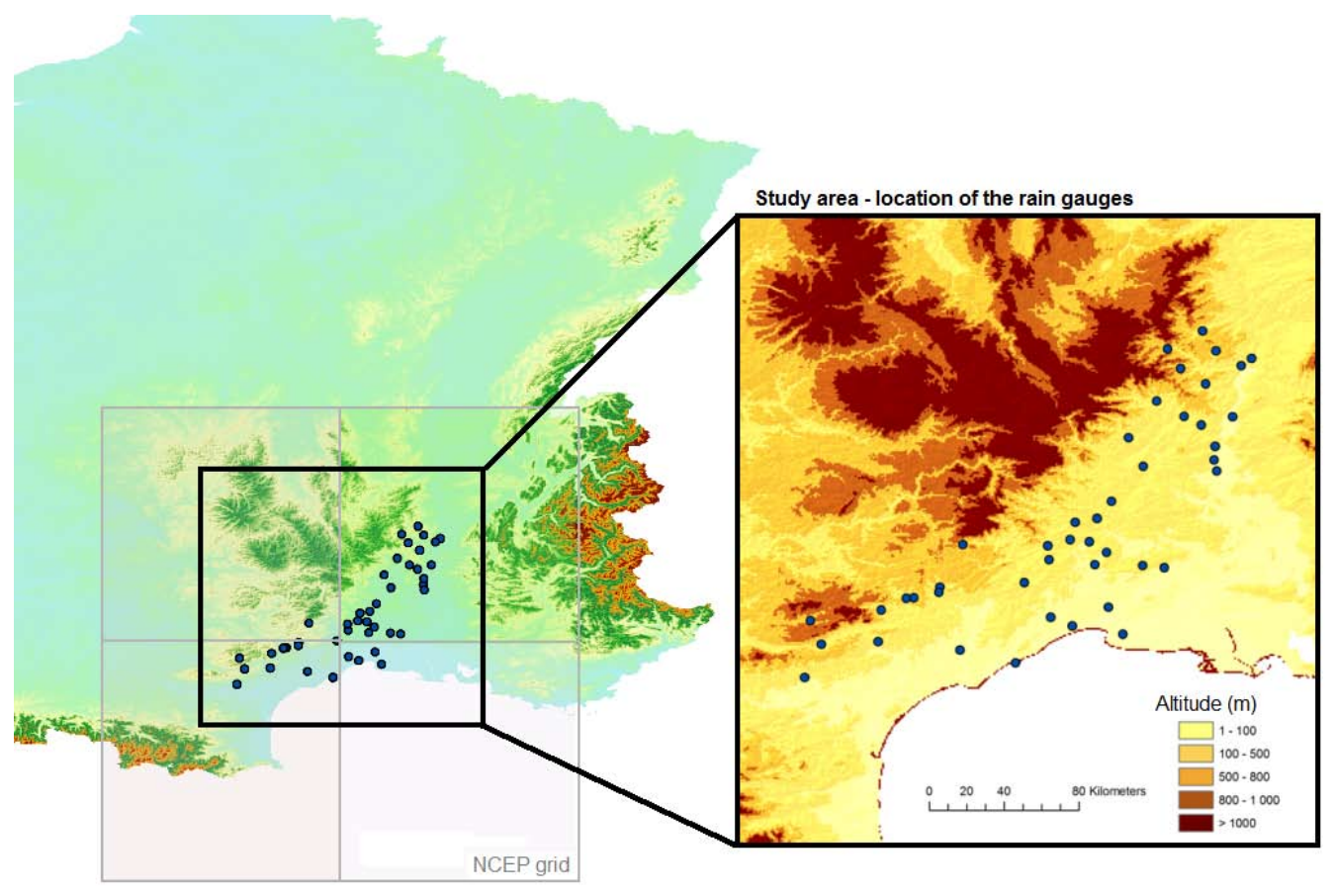

Fig. 1. Location of the 44 rain gauges in Southern France.

It was selected after verifications of the frequency model hypothesis with mean excess plots and a sensitivity analysis of the GP and Poisson distribution parameters to a range of different threshold values (Coles et al., 2003 or Beguería et al., 2010). Then a regional sampling approach was considered in order to avoid spatial and temporal correlations between the heavy rainfall events (Tzavelas et al., 2010). The sampling rules are a minimum of 2 days in between two consecutive events, and in the case of events occurring the same day in several stations, only the maximum value is conserved in the sample. The resulting sample includes 168 events.

\section{Frequency model}

A peaks-over-threshold (POT) model is considered in order to analyze both the occurrence process and the magnitude of heavy rainfall events (Coles, 2001; Coles et al., 2003; Tzavelas et al., 2010). The occurrence of threshold exceedances is assumed to follow a Poisson distribution and the magnitude of exceedances a Generalized Pareto (GP) distribution (Coles, 2001). The Poisson distribution has one parameter, $\lambda$, corresponding here to the average number of threshold exceedances during the fall season between 1958 and 2008. The Poisson probability distribution function (PDF) is given by:

$F(n)=\exp ^{-\lambda} \frac{\lambda^{n}}{n !}$
The GP distribution that models the threshold exceedances has 3 parameters: $\alpha$ the scale parameter, $\kappa$ the shape parameter, and $q_{0}$ the threshold level. The threshold level is determined a priori: here $q_{0}=100 \mathrm{~mm}$. The GP distribution has the following PDF:

$$
\begin{array}{ll}
F(q)=1+\left(1-\kappa \frac{q-q_{0}}{\alpha}\right)^{-1 / \kappa} & \kappa \neq 0 \\
F(q)=1-\exp \left(-\frac{q-q_{0}}{\alpha}\right) & \kappa=0
\end{array}
$$

The inclusion of covariate information is tested only on the $\lambda$ and $\alpha$ parameters, using a log-linear type of dependance:

$\theta(t)=\exp \left(b+a_{1} X_{1}+a_{2} X_{2} \ldots+a_{n} X_{n}\right)$

Where $\theta$ is the model parameter ( $\lambda$ or $\alpha$ ), $n$ the number of $X$ covariates, $a$ and $b$ parameters to be estimated. In the present study, the estimation of the stationary and non-stationary model parameters is performed through the Maximum Likelihood method.

The deviance statistic test based on the $\log$-likelihood $\left(l_{n} *\right)$ is chosen to compare the stationary $\left(M_{0}\right)$ and non-stationary $\left(M_{1}\right)$ models:

$D=2\left\{l_{n}^{*}\left(M_{1}\right)-l_{n}^{*}\left(M_{0}\right)\right\}$

Large values of $D$ indicate that the model $M_{1}$ is more adequate at representing the data than the model $M_{0}$. The $D$ statistic is distributed according to a chi-square distribution, with $v$ degrees of freedom, where $v$ is the difference between the number of parameters of the $M_{1}$ and $M_{0}$ models (Coles, 2001). 

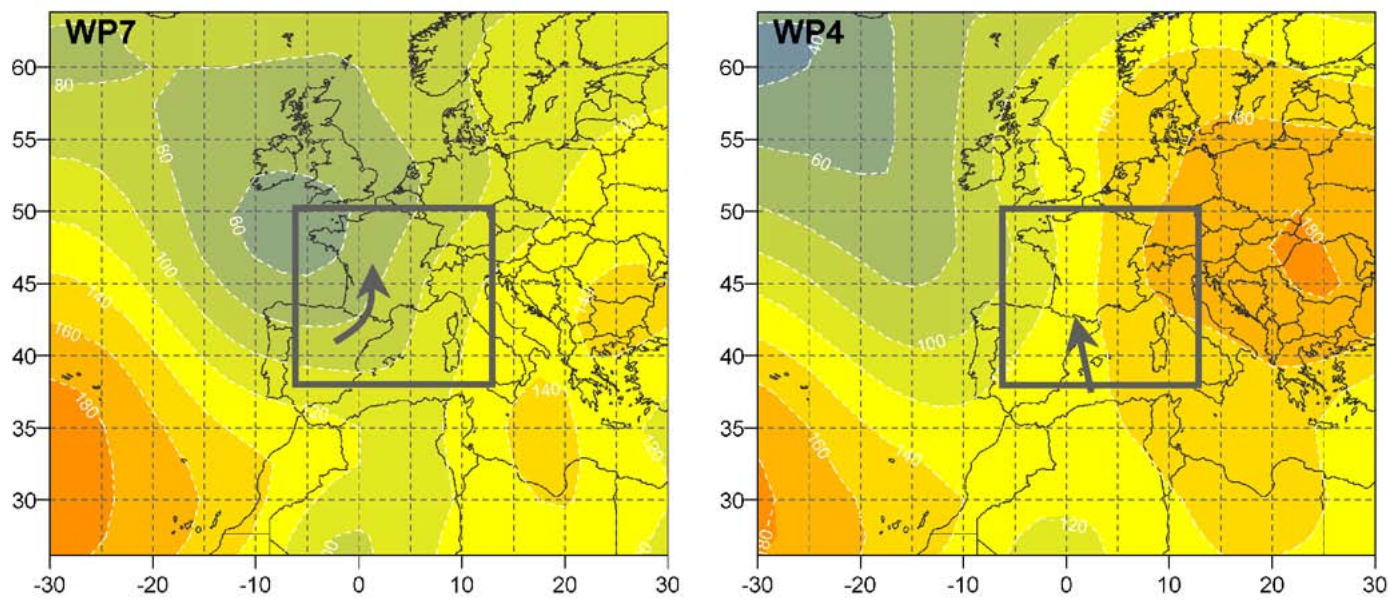

Fig. 2. Average geopotential height at $1000 \mathrm{hpa}$ for the weather patterns 7 and 4 of the EDF2006 classification (from Garavaglia et al., 2010). The arrows indicate the airflow, near the surface, induced by the prevailing synoptic conditions.

\section{Climatic datasets}

Several climatic covariates are tested to be included in the POT model, they include:

1. A classification (EDF-2006) of the synoptic patterns associated with rainfall events over France, developed by Paquet et al. (2006) and Garavaglia et al. (2010). This classification is based on the geopotential height fields at 700 and $1000 \mathrm{hPa}$ pressure levels for rainy days over France. The resulting 8 weather patterns (WP) provide a picture of the diversity of synoptic situations associated with rainfall over France. In particular, the patterns WP7 ("Central Depression") and WP4 ("South Circulation") shown in Fig. 2 are linked to Mediterranean circulations that usually bring heavy rains to south-eastern France (Paquet et al., 2006). The prevailing WP in fall during 1958-2008 are the WP8 (25\%), WP4 (22,8\%), and WP2 $(21.5 \%)$ when WP7 only account for $3.9 \%$ of the days. The frequencies of WP4 and WP7 each fall were computed in order to be tested as covariates.

2. NCEP/NCAR reanalysis data for atmospheric covariates at daily, monthly and annual time steps. The data from the four $2.5^{\circ} \times 2.5^{\circ}$ grid cells covering the region (Fig. 1) were extracted. Several studies have shown that heavy rainfall events in the study area were linked with the presence of moist and warm air associated with a strong, convergent southeasterly low-level flow (Joly et al., 2009). The variables considered include the mean sea level pressure (SLP), the potential temperature (PTEMP) and the air temperature (TEMP) at the surface level, specific humidity (SHUM), the geopotential height (HGT), and the $U$ and $V$ wind components at the 850 and $925 \mathrm{hPa}$ levels. The humidity flux (FHUM) from the Mediterranean Sea is computed as the product of the strength of south-easterly winds and the specific humidity.

3. The Mediterranean Oscillation (MO) index, defined by Conte et al. (1989) as the normalized pressure difference between Algiers $\left(36.4^{\circ} \mathrm{N}, 3.1^{\circ} \mathrm{E}\right)$ and Cairo $\left(30.1^{\circ} \mathrm{N}\right.$, $31.4^{\circ} \mathrm{E}$ ). The MO has been considered the most important regional low-frequency pattern influencing rainfall in the Mediterranean basin by some studies (e.g. Maheras et al., 1999). Therefore, its influence on heavy rainfall events in Southern France is tested.

4. Sea surface temperatures (SST) from NOAA-NCDC Extended Reconstructed Sea Surface Temperature Dataset (ERSST), Version 3b. The monthly analysis are available at a spatial grid resolution of $2^{\circ}$ from 1880 to present, and are retrieved for the grid pixels corresponding to the Mediterranean Sea in the Gulf of Lion. Previous studies have shown that heavy rainfall events occurring in the Southern French Mediterranean region are associated with warm anomalies of SST in the West Mediterranean Sea (Funatsu et al., 2009).

\section{Results}

The different covariates are tested in the non-stationary POT model. For each combination of covariates, the deviance score is computed between the stationary Poisson $\left(\mathrm{P}_{0}\right)$ model and the non-stationary Poisson $\left(\mathrm{P}_{1}\right)$ model including the covariate. The same approach is used for the GP distribution, between the stationary model $\mathrm{GP}_{0}$ and the non stationary model $\mathrm{GP}_{1}$ with covariate. In Tables 1 and 2 are presented the deviance scores significant at the $5 \%$ level. For the Poisson distribution (Table 1), several covariates computed during the fall season are found to improve the model. These 


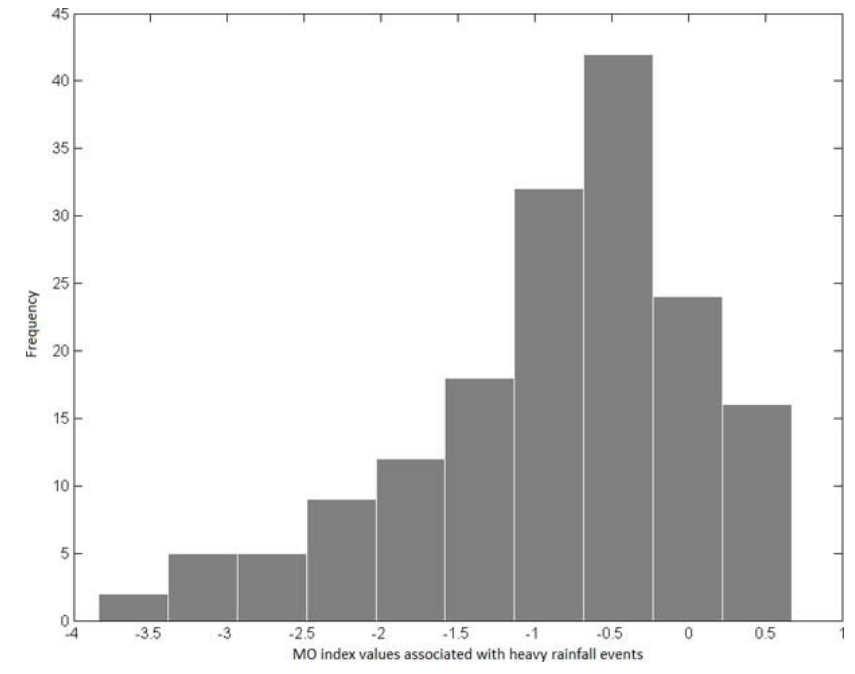

Fig. 3. Daily Mediterranean Oscillation Index values associated with heavy rainfall events.

variables include the frequency of the WP4 and WP7, the humidity flux in the low layers of the atmosphere (FHUM925), and to a lesser extend the air temperature and SST. This indicates that either an increase in the frequency of WP4 or WP7, in the humidity flux, in air termperature, or in sea surface temperature during the fall season is associated with an increased number of heavy rainfall events.

For the GP distribution, as shown in Table 2, several covariates computed at a monthly time scale from the NCEP reanalysis can also improve the model. In particular, the temperature associated with the sea level pressure yield the largest deviance score. The humidity flux from the Mediterranean Sea (FHUM925), the geopotential height at the $850 \mathrm{hPa}$ level (HGT850), and the meridional wind component at the $925 \mathrm{hPa}$ level (V925) also significantly improve the model. Therefore, an increase in the monthly average of these climatic parameters is associated with an increased intensity of the heavy rainfall events. Monthly or seasonal SST values are not found to be valid covariates in the GP model. Finally, time as a covariate also provide a significant deviance score when included in the $\mathrm{GP}_{1}$ model, indicating an increasing trend in the intensity of heavy rainfall events during the observation period.

The MO index is not found to improve the Poisson nor the GP model when considering monthly or seasonal averaged MO index values. Nevertheless, the heavy rainfall events are mostly associated with negative daily values of the MO index. Figure 3 shows the distribution of the MO index values associated with the different events. VicenteSerrano et al. (2009) also found that atmospheric circulation indexes at daily timescales seem to be more appropriate than monthly indexes when describing the influence of atmospheric circulation on the risk of heavy precipitation. However, to make future projections there is a need to incorporate
Table 1. Deviance statistic for the covariates tested with the Poisson distribution.

\begin{tabular}{lr}
\hline $\begin{array}{l}\text { Covariates tested with } \\
P_{1} \text { (SON averages) }\end{array}$ & $\begin{array}{r}\text { Deviance } \\
\text { statistic }\end{array}$ \\
\hline Frequency of WP4 & 14.31 \\
FHUM925 & 14 \\
Frequency of WP7 & 7.19 \\
SST & 5.7 \\
TEMP & 4.8 \\
\hline
\end{tabular}

Table 2. Deviance statistic for the covariates tested with the GP distribution.

\begin{tabular}{lr}
\hline $\begin{array}{l}\text { Covariates tested with } \\
\text { GP }_{1} \text { (monthly averages) }\end{array}$ & $\begin{array}{r}\text { Deviance } \\
\text { statistic }\end{array}$ \\
\hline TEMP + SLP & 12.89 \\
HGT850 & 11.64 \\
FHUM925 & 9.07 \\
SLP & 8.33 \\
V925 & 6.31 \\
TEMP & 5.8 \\
PTEMP & 4.68 \\
Time & 4.35 \\
\hline
\end{tabular}

in non-stationary models time-averaged covariates, since the global climate models are better at producing a climatology rather than day-to-day chronology.

With the possible covariates identified, it becomes possible to propose functional relationships between the POT model parameter and climatic covariates. The frequency of WP4 in fall (fWP4) is selected as covariate for the $\lambda$ parameter of the Poisson distribution:

$\lambda(\mathrm{fWP} 4)=\exp (0.29 \mathrm{fWP} 4-3.36)$

As shown in Fig. 4 , the non-stationary $\lambda_{\text {ns }}$ parameter can vary from 1.8 to 6 , when for the stationary distribution $\lambda_{s}=3.22$. Similarly, the scale parameter $\alpha$ of the GP distribution is related to the monthly air temperature and seal level pressure with the following:

$\alpha($ SLP, TEMP $)=\exp (0.75$ SLP +0.06 TEMP -92.65$)$

The shape parameter is equal to 0.042 for the stationary GP and to 0.035 for the non-stationary GP, indicating similar heavy tailed distributions. For the stationary GP model, $\alpha_{\mathrm{s}}=54.98$, whereas in the non-stationary model (Fig. 5) $\alpha_{\mathrm{ns}}$ can vary from 26.3 to 93.47 , depending on the values taken by the covariates SLP and TEMP. 


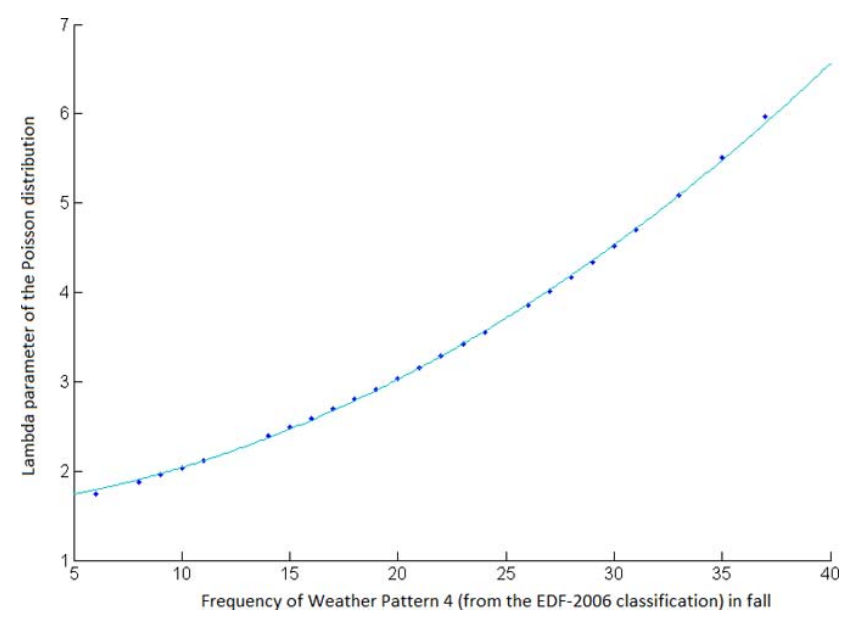

Fig. 4. Relationship between the number of heavy rainfall events and the frequency of WP4 in fall.

\section{Summary and conclusions}

Several covariates have been tested to be included in a POT model for heavy rainfall events in Southern France. Nonstationary models, with their parameter dependent on covariates, have been compared with classical stationary models with fixed parameters using the statistical deviance test. Several covariates are found to improve the POT model. In particular, the frequency of southern-circulation patterns (WP4 and WP7 in the EDF-2006 classification), the humidity flux from the Mediterranean Sea, air temperature, and sea surface temperatures appear as valid predictors for the occurrence process of heavy rainfall events. For the intensity of the events, the sea level pressure with air temperature are the best predictors. Such non-stationary models that include climatic covariates can help explain the relationships between the extreme events and the associated physical and climatic processes. With model parameters dependent on climatic covariates, the next step would be to use the outputs of General Circulation Models to predict the evolution of the possible values taken by the covariates in the future. This approach provides a way to evaluate the future changes in the frequency or the magnitude of heavy rainfall events induced by the global warming. It also gives the possibility to re-evaluate the quantiles of different return periods on a seasonal basis, hence allowing a better risk assessment in the context of climate change. Other non-stationary models need to be tested that also include covariate information on the shape parameter of the GP distribution.

Acknowledgements. This research was done in the context of the EXTRAFLO program (ANR RiskNat). Météo-France is gratefully acknowledged for providing the daily rainfall data series. Thanks are also due to Joel Gailhard and Emmanuel Paquet (EDF) for providing the EDF-2006 classification data. The authors would also like to thank the editor of this special issue, Aristides Bartzokas, and the three reviewers for their comments.

Edited by: A. Bartzokas

Reviewed by: three anonymous referees

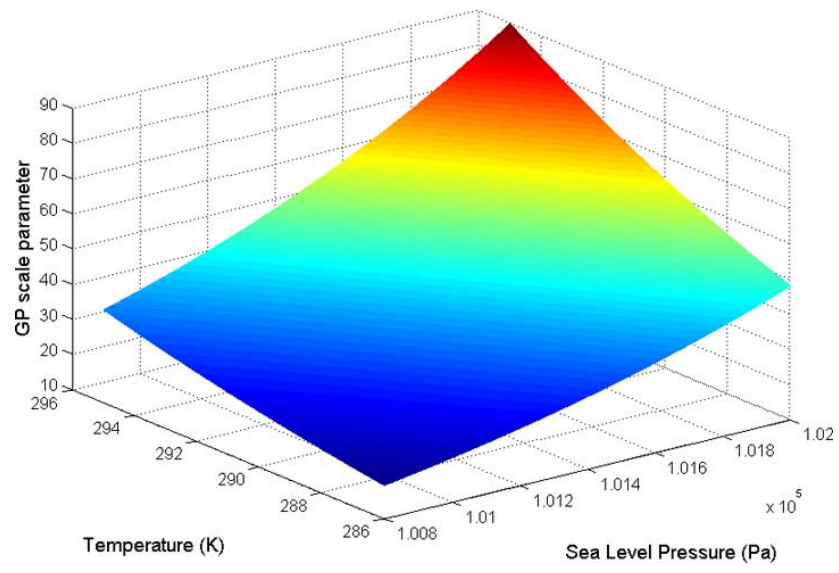

Fig. 5. Relationship between the scale parameter of the GP distribution and monthly temperature and sea level pressure.

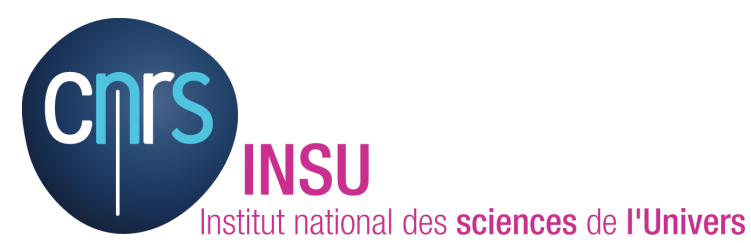

The publication of this article is financed by CNRS-INSU.

\section{References}

Beguería, S., Angulo-Martínez, M., Vicente-Serrano, M., LópezMoreno, J. I., and El-Kenawy, H.: Assessing trends in extreme precipitation events intensity and magnitude using non-stationary peaks-over-threshold analysis: a case study in northeast Spain from 1930 to 2006, Int. J. Climatol., doi:10.1002/joc.2218, 2010.

Boissier, L. and Vinet, F.: Paramètres hydroclimatiques et mortalité due aux crues torrentielles, Etude dans le sud de la France, in: Actes du 22ème colloque de l'Association Internationale de Climatologie, Geographia Technica, Cluj University Press, Romania, 2009 (in French).

Coles, G. S.: An Introduction to Statistical Modeling of Extreme Value, Springer-Verlag, Heidelberg, Germany, 2001.

Coles, S., Perrichi, L. R., and Sisson, S.: A fully probabilistic approach to extreme rainfall modeling, J. Hydrol., 273, 35-50, 2003.

Conte, M., Giuffrida, A., and Tedesco, S.: The Mediterranean Oscillation. Impact on precipitation and hydrology in Italy Climate Water, Publications of the Academy of Finland, Helsinki, 1989.

Funatsu, B. M., Claud, C., and Chaboureau, J. P.: Comparison between the Large-Scale Environments of Moderate and Intense Precipitating Systems in the Mediterranean Region, Mon. Weather Rev., 137, 3933-3959, doi:10.1175/2009MWR2922.1, 2009.

Garavaglia, F., Gailhard, J., Paquet, E., Lang, M., Garçon, R., and Bernardara, P.: Introducing a rainfall compound distribution 
model based on weather patterns sub-sampling, Hydrol. Earth Syst. Sci., 14, 951-964, doi:10.5194/hess-14-951-2010, 2010.

Giogi, F. and Lionello, P.: Climate change projections for the Mediterranean region, Glob. Planet. Change, 63, 90-104, 2008.

Goubanova, K. and Li, L.:Extremes in temperature and precipitation around the Mediterranean basin in an ensemble of future climate scenario simulations, Glob. Planet. Change, 57, 27-42, 2007.

Joly, B., Nuissier, O., Ducrocq, V., and Joly, A.: Mediterranean synoptic-scale ingredients involved in heavy precipitations events triggering over southern France: a clustering approach, in: proceeding of ICAM, International conference on alpine meteorology, Chambery, France, 2007.

Katz, R. W., Parlange, M. B., and Naveau, P.: Statistics of extremes in hydrology, Adv. Water Res., 25, 1287-1304, 2002.

Maheras, P., Xoplaki, E., and Kutiel, H.: Wet and dry monthly anomalies across the Mediterranean basin and their relationship with circulation, 1860-1990, Theor. Appl. Climatol., 64, 189199, 1999.
Nastos, P. T. and Zerefos, C. S.: Decadal changes in extreme daily precipitation in Greece, Adv. Geosci., 16, 55-62, doi:10.5194/adgeo-16-55-2008, 2008.

Paquet, E., Gailhard, J., and Garçon, R.: Evolution of GRADEX method: improvement by atmospheric circulation classification and hydrological modeling, La Houille Blanche, 5, 80-90, 2006.

Pujol, N., Neppel, L., and Sabatier, R.: Regional tests for trend detection in maximum precipitation series in the French Mediterranean region, Hydrol. Sci. J., 52, 956-973, 2007.

Tzavelas, G., Paliatsos, A. G., and Nastos, P. T.: Brief communication "Models for the exceedances of high thresholds over the precipitation daily totals in Athens, Greece", Nat. Hazards Earth Syst. Sci., 10, 105-108, doi:10.5194/nhess-10-105-2010, 2010.

Vicente-Serrano, S. M., Beguería, S., López-Moreno, J. I., El Kenawy, A. M., and Angulo-Martínez, M.: Daily atmospheric circulation events and extreme precipitation risk in northeast Spain: Role of the North Atlantic Oscillation, the Western Mediterranean Oscillation, and the Mediterranean Oscillation, J. Geophys. Res., 114, D08106, doi:10.1029/2008JD011492, 2009. 